\title{
Anterior vitriotomy for aphakic flat anterior chamber
}

\author{
EDWARD GOTLIER
}

From the Department of Ophthalmology, University of Illinois Eye and Ear Infirmary, University of Illinois at the Medical Center, Chicago, Illinois

In a retrospective study of flat anterior chamber after cataract extraction, which was carried out at the University of Illinois Eye and Ear Infirmary (1959-1970), an incidence of $7.5^{8}$ per cent. was found among 8,553 cases. Re-formation of the anterior chamber usually occurred after therapy with mydriatics (Reese, I949), miotics, acetazolamide (Thorpe, I954), or osmotic agents (Jaffe and Light, I966). Surgical therapy, consisting of air or saline injection into the anterior chamber (Kronfeld, I957), drainage of choroidal detachments (Kronfeld, I957), or iridectomy (Ghandler and Johnson, I947), was required for aphakic eyes with flat anterior chamber unresponsive to medical therapy. The present communication reports four cases in which aphakic eyes with a flat anterior chamber were unresponsive to many of the procedures mentioned above but did respond to incision of the anterior hyaloid (anterior vitriotomy).

\section{Case reports}

FLAT ANTERIOR GHAMBER NOT RELIEVED BY IRIDECTOMY. VITRIOTOMY NOT DONE

Case I. A 74-year-old Negro female, with a i4-year history of diabetes mellitus, had bilateral diabetic-senile cataracts. The visual acuity was $20 / 200$ in the right eye and 20/200 in the left.

An uncomplicated intracapsular cataract extraction was performed on the right eye on October $\mathrm{I}$, 1964, without vitreous loss. The lens was delivered with capsule forceps after peripheral iridectomy. The wound was closed with three $7-0$ silk sutures. The patient's progress for the first 90 days is shown in Fig. I.

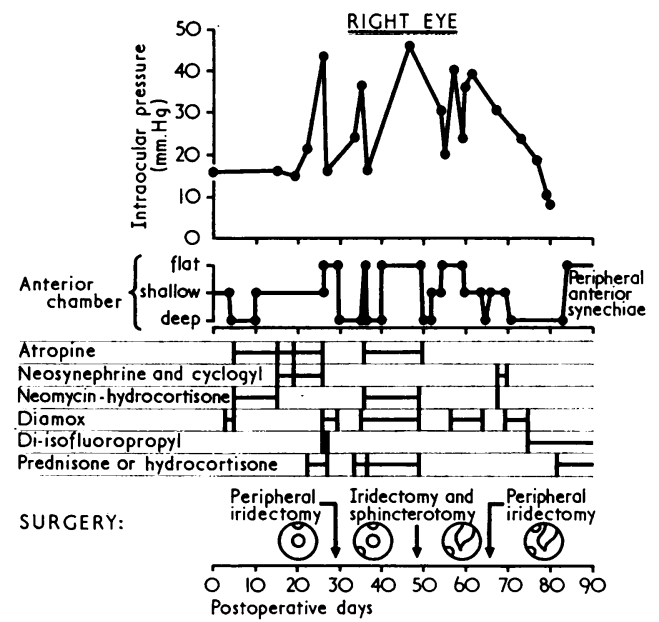

FIG. I Case I. Flat anterior chamber not relieved by iridectomy. Vitriotomy not done. Medications to right eye:

gutt. atropine I per cent. twice daily; gutt. Neosynephrine ro per cent. and Cyclogyl I per cent. three times a day;

gutt. neomycin-hydrocortisone 0.1 per cent. twice daily;

acetazolamide (Diamox) $250 \mathrm{mg}$. four times a day;

gutt. dyflos 0.25 per cent. twice daily;

gutt. prednisone $0 \cdot 1$ per cent. twice daily

Received for publication June I, 197

Address for reprints: E. Cotlier, M.D., Department of Ophthalmology, University of Illinois Eye and Ear Infirmary, University of Illinois at the Medical Center, Chicago, Illinois 
On the first and second postoperative days a shallow anterior chamber was noted. It deepened spontaneously, but 14 days later was again found to be shallow. The intraocular pressure was $16 \mathrm{~mm} . \mathrm{Hg}$. A flat anterior chamber that deepened after instillation of mydriatics was again noted at return visits on the $19^{\text {th }}$ and 22 nd postoperative days. On the 26 th day, the anterior chamber was flat and the intraocular pressure was $43 \mathrm{~mm}$. $\mathrm{Hg}$.

The patient was given alternating mydriatic-miotic therapy, and this lowered the intraocular pressure to $15 \mathrm{~mm}$. $\mathrm{Hg}$. Gonioscopy revealed that the angles were occluded for $270^{\circ}$, the iridectomy was blocked by the anterior hyaloid, and pigmented trabeculum was visible for $90^{\circ}$.

On the 29th day a right peripheral iridectomy was performed at the 7 o'clock position and the anterior chamber deepened.

On the $35^{\text {th }}$ day a blood clot blocked the new iridectomy and the anterior chamber again became flat, the intraocular pressure being $36 \mathrm{~mm}$. Hg. After topical mydriatics and o 1 per cent. prednisone, the anterior chamber deepened, but on the 43rd day it was again flat, and choroidal detachments were noted. The intraocular pressure on the $47^{\text {th }}$ day was $46 \mathrm{~mm}$. $\mathrm{Hg}$.

On the 49th day another iridectomy was performed together with sphincterotomy. The anterior chamber remained deep for 2 days, but then became flat.

On the 54th day the intraocular pressure was $30 \mathrm{~mm}$. $\mathrm{Hg}$. Diamox $125 \mathrm{mg}$. four times a day was again administered, but the pressure on days 60 and 6 I was 36 and $39 \mathrm{~mm}$. $\mathrm{Hg}$ respectively.

A new peripheral iridectomy was performed and $\mathrm{I} \mathrm{ml}$. liquid vitreous was aspirated through the limbal incision on the 63 rd day, but the anterior chamber remained shallow, and the eye became very painful. The intraocular pressure was $30 \mathrm{~mm}$. $\mathrm{Hg}$ on the 67 th postoperative day. Diamox $250 \mathrm{mg}$. four times a day and topical $0 \cdot 1$ per cent. dyflos maintained the intraocular pressure at about 16 to $24 \mathrm{~mm}$. Hg. All medication was discontinued from the 8oth day.

\section{Result}

6 months after cataract surgery the right eye was blind. Gonioscopy revealed peripheral anterior synechiae for $300^{\circ}$, and the intraocular pressure was $9 \mathrm{~mm}$. Hg. The persisting hypotony suggested early phthisis bulbi.

\section{ANTERIOR VITRIOTOMY FOR THERAPY OF PUPILLARY BLOCK FLAT}

\section{ANTERIOR GHAMBER NOT RELIEVED BY IRIDEGTOMY}

Case 2. A 46-year-old Negro female, with a mature cataract in the left eye and initial lens changes in the right, had a visual acuity of $20 / 30$ in the right eye and perception of light in the left.

She underwent an uncomplicated intracapsular cataract extraction in the left eye on August $\mathrm{I}$, 1969. The lens was delivered without vitreous loss with the cryoextractor after a peripheral iridectomy. The wound was closed with six $7-0$ chromic catgut sutures. The immediate postoperative period was uneventful. The progress for the first 8o days is shown in Fig. 2.

At the return visit 13 days postoperatively, a flat anterior chamber and choroidal detachments were detected. The intraocular pressure was $12 \mathrm{~mm}$. $\mathrm{Hg}$ in the left eye, and a Seidel test was negative. She was treated with mydriatics topically and one oral dose of glycerol $100 \mathrm{ml}$. The anterior chamber remained flat despite the addition of Diamox $250 \mathrm{mg}$. four times a day.

On the 18 th postoperative day, a posterior sclerotomy, drainage of choroidal detachments, and reformation of the anterior chamber with air and saline were performed, but the chamber remained flat and shallow.

Gonioscopy on the 24th and $3^{2 n d}$ postoperative days indicated that the angles were occluded for $270^{\circ}$, the only open area corresponding to the iridectomy. The intraocular pressure on the $33 \mathrm{rd}$ day was $21 \mathrm{~mm}$. $\mathrm{Hg}$ in the right eye and $23 \mathrm{~mm}$. $\mathrm{Hg}$ in the left.

The patient returned 55 days postoperatively, when the visual acuity was $20 / 25$ and the intraocular pressure $38 \mathrm{~mm}$. $\mathrm{Hg}$ in the left eye. There was pupillary and iridectomy blockade by the anterior hyaloid membrane.

Two additional iridectomies at I I and I o'clock, performed on the 56 th postoperative day, resulted 


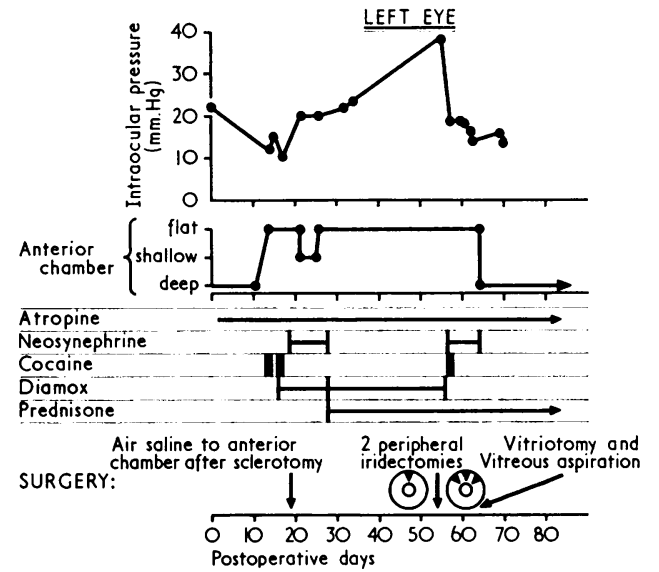

FIG. 2 Case 2. Vitriotomy for therapy of pupillary block flat anterior chamber. Medications to left eye:

gutt. atropine I per cent. three times a day; gutt. Neosynephrine ro per cent. four times a day;

gutt. cocaine I per cent. four times a day; acetazolamide (Diamoc) $250 \mathrm{mg}$. four times a day; gutt. prednisone $0 \cdot 1$ per cent. twice daily

in a lowering of the intraocular pressure, but the anterior chamber remained flat. A repeat Seidel test was negative.

On the 63 rd postoperative day the anterior hyaloid membrane was incised, and the anterior chamber developed aphakic depth immediately. An attempt to aspirate vitreous from the vitreous cavity through an i 8-gauge needle was unsuccessful.

Result

Gonioscopy showed $180^{\circ}$ of the angles closed with peripheral anterior synechiae 6 months after cataract surge1y, with visual acuity $20 / 20$ and intraocular pressure $18 \mathrm{~mm}$. $\mathrm{Hg}$ in the left eye. The eye remains the same one year after surgery.

The patient later underwent uncomplicated cataract surgery in the other eye.

Case 3. A 63-year-old Negro female had a mature cataract in the left eye, minimal lens changes in the right eye, and a visual acuity of 20/30 in the right eye and hand movements in the left.

She underwent an uncomplicated intracapsular cataract extraction in the left eye on March I2, ig6o.

The lens was delivered without vitreous loss with the cryoextractor after peripheral iridectomy. The wound was closed with three $7-0$ chromic catgut sutures. The immediate postoperative period was uneventful, and the patient was discharged on I per cent. atropine drops and Neosporin drops once a day to the left eye (Fig. 3).

At the first visit 15 days postoperatively, the anterior chamber of the left eye was found to be shallow, but deepened immediately after instillation of atropine I per cent. drops, cocaine I per cent. drops, and Neosynephrine to per cent. drops. Choroidal detachments were not present.

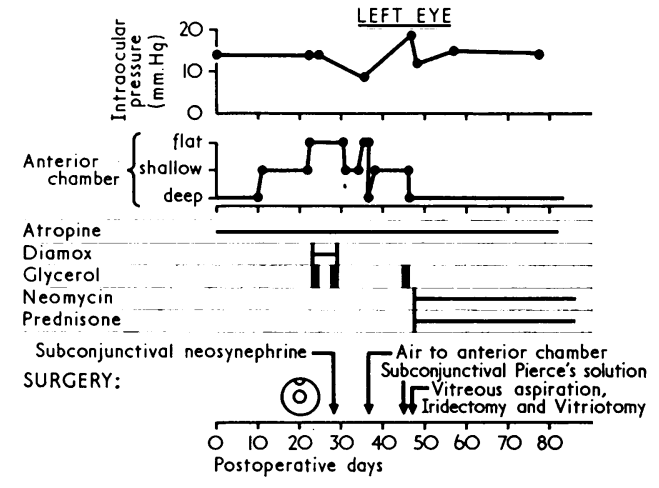

F1G. 3 Case 3. Vitriotomy for therapy of pupillary block flat anterior ihamber. Medications to left eye:

gutt. atropine iper cent. three times a day; acetazolamide (Diamox) $250 \mathrm{mg}$. four times a day;

glycerol 5o per cent. (Osmoglyn) $120 \mathrm{ml}$. oral; gutt. neomycin twice daily;

gutt. prednisone $0 \cdot 1$ per cent. twice daily

Pierce's solution: phenylephrine $\mathrm{HCl} 0.5$ per cent.; homatropine hydrobromide 0.4 per cent.; procaine hydrochloride 1 per cent.; sodium bisulphite $0 \cdot 1$ per cent.; sodium citrate 0.4 per cent.; benzyl alcohol I 0 per cent.; sodium chloride 0.26 per cent.; in distilled water 
On the 22nd postoperative day the anterior chamber was flat, and instillation of mydriatics failed to deepen it. The intraocular pressure in the left eye was $13 \mathrm{~mm}$. $\mathrm{Hg}$, a Seidel test on the $23 \mathrm{rd}$ postoperative day was negative, and there was no other evidence of external filtration. In addition to mydriatics (as above), Diamox $250 \mathrm{mg}$. four times a day and oral glycerol $100 \mathrm{ml}$. were given. The anterior chamber remained flat, and on the 28th postoperative day subconjunctival neosynephrine I.5 per cent. was administered with oral glycerol $120 \mathrm{ml}$. Diamox capsules were discontinued. The depth of the anterior chamber increased, but on the $35^{\text {th }}$ postoperative day it was flat again, the intraocular pressure being $8 \mathrm{~mm}$. Hg. Choroidal detachments were not detected.

On the 36 th postoperative day the anterior chamber was re-formed with air; it remained deep for 2 days and then became shallow with vitreous protruding through the pupil and in contact with the cornea. On the $45^{\text {th }}$ day postoperatively, $0 \cdot 3 \mathrm{ml}$. Pierce's solution was injected subconjunctivally into the left eye, but the anterior chamber remained shallow and the intraocular pressure was $19 \mathrm{~mm}$. Hg. The next day a left posterior sclerotomy was performed and $0.5 \mathrm{ml}$. vitreous was aspirated, but the anterior chamber did not re-form. A full iridectomy was then made through a limbal incision at the 3 o'clock position, but the anterior chamber did not increase in depth. Finally, a Ziegler knife was introduced into the anterior chamber and the anterior hyaloid was incised by a cruciate incision. The anterior chamber then deepened immediately, and an additional $0.3 \mathrm{ml}$. vitreous was aspirated. The anterior chamber remained deep and the intraocular pressure was 12, 15 and $18 \mathrm{~mm}$. $\mathrm{Hg}$ on the $47_{\mathrm{th}}, 56 \mathrm{th}$, and $64^{\text {th }}$ days, while she was receiving topical atropine I per cent. drops and Neo-Cortef drops four times a day.

Result

Later, a large opening of the hyaloid was seen. The visual acuity was $20 / 40$ and gonioscopy revealed angles with peripheral anterior synechiae for $160^{\circ} ; 9$ months later there had been no change and the intraocular pressure was $18 \mathrm{~mm}$. $\mathrm{Hg}$.

Case 4, a 66-year-old Negro male, had undergone an uncomplicated cataract extraction in the right eye 3 years previously.

On admission the visual acuity was 20/30 (with correction) in the right eye and 20/100 in the left. There was an immature cataract in the left eye. The intraocular pressure was $15 \mathrm{~mm}$. Hg in the right eye and $16 \mathrm{~mm} . \mathrm{Hg}$ in the left (applanation tonometry). Gonioscopy revealed wide open angles in both eyes.

On August 8, 1969, an intracapsular cataract extraction was performed on the left eye without vitreous loss. A peripheral iridectomy was made and the wound closed by three 8 -o silk sutures (Fig. 4).

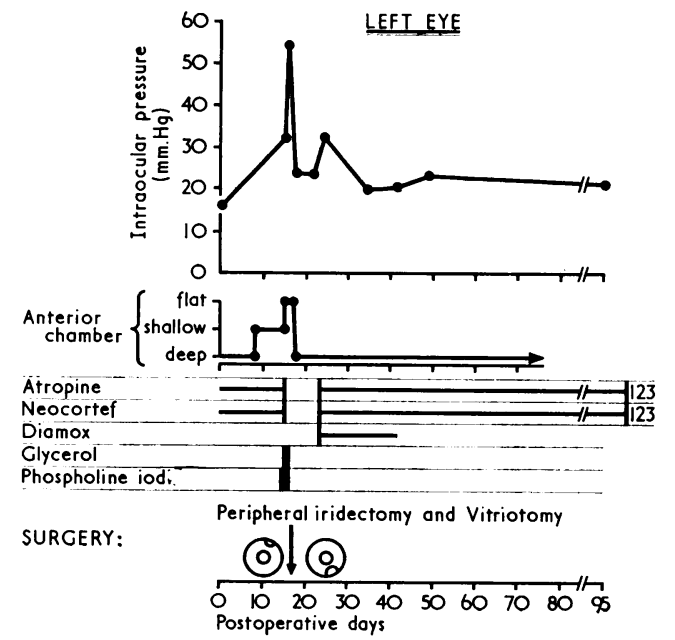

FIG. 4 Case 4. Vitriotomy for therapy of pupillary block flat anterior chamber. Top graph, ordinate: intraocular pressure $(\mathrm{mm} . \mathrm{Hg})$; abscissa, days since cataract surgery. Medications to left eye as follows:

Atropine I per cent. drops twice daily

Neo-Cortef drops twice daily, acetazolamide (Diamox) $250 \mathrm{mg}$. four times a day, glycerol (Osmoglyn) roo ml. orally; Phospholine Iodide $0 \cdot 25$ per cent. drops twice daily 
The immediate postoperative period was complicated by a shallow anterior chamber discovered 8 days postoperatively. The vitreous face was bulging through the pupil, and choroidal detachments were present. Atropine I per cent. drops and Neo-Cortef drops to the left eye were continued. On the $1^{\text {th }}$ postoperative day the anterior chamber was flat, and the vitreous face was bulging and in contact with the cornea. The intraocular pressure was $16 \mathrm{~mm}$. $\mathrm{Hg}$ in the right eye and $32 \mathrm{~mm} . \mathrm{Hg}$ in the left. Gonioscopy revealed totally closed angles. Therapy was begun with glycerol $100 \mathrm{ml}$. orally and Phospholine Iodide $0 \cdot 25$ per cent. drops; the intraocular pressure was $22 \mathrm{~mm}$. $\mathrm{Hg}$.

On the 17 th postoperative day an iridectomy was performed on the left eye, but the anterior chamber did not deepen. Through the same limbal opening a vitriotomy and vitreous aspiration were performed, and the anterior chamber deepened immediately. The intraocular pressure was $32 \mathrm{~mm} . \mathrm{Hg}$ on the 23rd postoperative day. Therapy with Diamox $250 \mathrm{mg}$. four times a day was added to atropine twice daily and Neo-Cortef drops four times a day to the left eye. On the 4 Ist postoperative day Diamox was discontinued.

Result

6 months after the operation the visual acuity in the left eye was $20 / 40$ and the intraocular pressure 2 I mm. Hg and there was a small iris prolapse at i i o'clock, covered by conjunctiva. The fundus and optic disc of the left eye were normal and the visual fields within normal limits.

I year postoperatively the intraocular pressure was $12 \mathrm{~mm}$. $\mathrm{Hg}$; there were $180^{\circ}$ peripheral anterior synechiae by gonioscopy and the iridectomy sites of the left eye were occluded by the anterior hyaloid. The visual acuity has remained $20 / 40$.

Case 5, a 69-year-old white male, underwent an uncomplicated cataract extraction in the left eye. On admission the visual acuity was 20/30 in the left eye and 20/200 in the right; there was an immature cataract in the right eye. On May 26, 1970, an intracapsular cataract extraction was performed in the right eye without vitreous loss. A peripheral iridectomy was made and the wound closed with five 7 -o silk sutures. On the 3 rd postoperative day a shallow anterior chamber was noted; the anterior hyaloid was protruding through the pupil and in contact with the cornea. Despite dilatation therapy with topical mydriatics, the anterior chamber continued shallow and flat (Fig. 5).

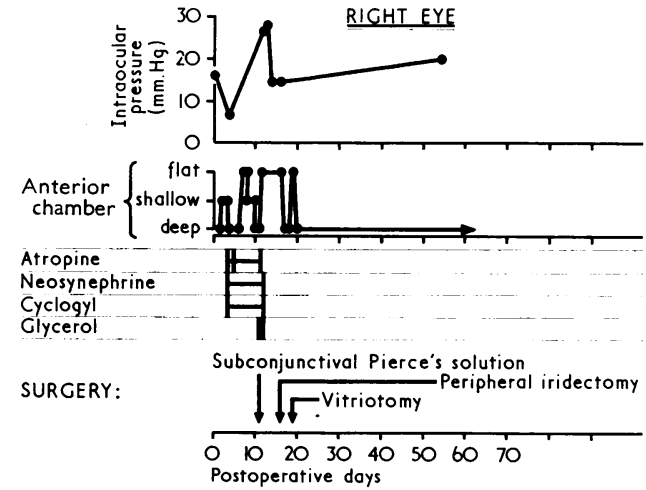

FIG. 5 Case 5. Vitriotomy for therapy of pupillary block flat anterior chamber. Top graph, ordinate: intraocular pressure in $\mathrm{mm}$. $\mathrm{Hg}$; abscissa: days since cataract surgery. Medications to right eye as follows:

Atropine I per cent. drops twice daily, Neosynephrine to per cent. drops twice daily, Cyclogyl I per cent. drops twice daily, glycerol 50 per cent. (Osmoglyn) $180 \mathrm{ml}$. orally.

On the I Ith postoperative day the intraocular pressure was $26 \mathrm{~mm}$. $\mathrm{Hg}$, and a subconjunctival injection of Pierce's solution was made and oral glycerol $\mathrm{I} 8 \mathrm{o} \mathrm{ml}$. in one dose was given. The intraocular pressure fell to i $\mathrm{mm}$. $\mathrm{Hg}$, but the next day the anterior chamber flattened again, and the intraocular pressure was $14 \mathrm{~mm}$. $\mathrm{Hg}$. The anterior chamber remained flat, and on the $\mathrm{I} 7$ th postoperative day a peripheral iridectomy was performed that deepened the anterior chamber.

On the I8th postoperative day the anterior chamber flattened again, an anterior vitriotomy was made with a Ziegler knife, and the chamberdeepened. Better pupillary dilatation allowed peripheral fundus examination, and choroidal detachments were detected. 
Six months later the visual acuity in the left eye was $20 / 30$ with correction, and $180^{\circ}$ of the angle was occluded by peripheral anterior synechiae. The intraocular pressure in both eyes was I I $\mathrm{mm} \mathrm{Hg}$ (applanation tonometry), and the fundus was normal.

\section{Discussion}

The herniation of the hyaloid face into the anterior chamber or a large area of iris-vitreous contact can result in pupillary block after cataract extraction. Reese (1949) recognized the effects of mydriatics in breaking the pupillary block with resulting spontaneous reformation of the anterior chamber in aphakic eyes. Priestley Smith (189I) suggested iridectomies or iridotomies for pupillary block aphakic flat anterior chamber with increased intraocular pressure. The beneficial effects of iridectomy in such eyes were well documented by Chandler ( $196 \mathrm{I}$ ). However, reports on aphakic eyes with pupillary block not responsive to iridectomy or iridotomy are lacking. Rather than abandon the eyes to inevitable secondary glaucoma, we found that incision of the vitreous face resulted in the re-formation of the anterior chamber with a good visual prognosis (Cases 2, 3, 4, and 5).

Incisions of the vitreous face were suggested by Shaffer (1954) as one of the few choices remaining for eyes with malignant glaucoma, if the extraction of the lens did not relieve a high intraocular pressure and flat anterior chamber. The cases reported above may have had accumulation of fluid in the vitreous cavity and this may have caused the flat anterior chamber to be unresponsive to the iridectomies but responsive to anterior vitriotomy. Case I represents an example of the poor visual prognosis of such eyes when vitriotomy is not performed. In contrast to eyes with malignant glaucoma, the aphakic flat anterior chambers in the eyes described above occurred in those which had not received filtering procedures or iridectomies and in which the preoperative intraocular pressures were normal.

Anterior vitriotomy is a simple procedure consisting of the introduction of a Ziegler or Wheeler knife into the anterior chamber and the incision of the vitreous face in a cruciate fashion. No vitreous loss was experienced in our cases as the fluid (? aqueous) retained by the vitreous cavity filled the anterior chamber immediately after the hyaloid incision. Anterior vitriotomy should, however, be reserved for aphakic eyes with flat anterior chamber and pupillary block unresponsive to medical therapy or iridectomy.

\section{Summary}

Five cases are presented of pupillary block aphakic flat anterior chamber unresponsive to mydriatics, miotics, acetazolamide, osmotic agents, or iridectomy. As a last surgical resort, four of these eyes were treated by anterior vitriotomy and retained good visual acuity without developing secondary glaucoma.

\section{References}

Chandler, P. A. (1961) Trans. Amer. Acad. Ophthal. Otolaryng., 65, 563

- and Johnson, c. c. (1947) Arch. Ophthal. (Chicago), 37, 740

JAFFE, N. s., and LIGHT, D. s. (I966) Ibid., 75, 370

KRONFELD, P. C. (1957) In "Management of Complications in Eye Surgery", ed. R. M. Fasanella, p. 195. Saunders, Philadelphia

REESE, A. B. (1949) Amer. F. Ophthal., 32, 933

Shaffer, R. N. (1954) Trans. Amer. Acad. Ophthal. Otolaryng, 58, 217

SMITH, PRIESTLEY (189I) "On the Pathology and Treatment of Glaucoma". Churchill, London

THORPE, H. E. (1955) "XVII Concilium Ophthalmologicum, 1954, Canada, U.S.A. Acta", vol. 3,

p. 1855 